\title{
Mass Color Assessment
}

National Cancer Institute

\section{Source}

National Cancer Institute. Mass Color Assessment. NCI Thesaurus. Code C92649.

A measurement of the color of a benign or malignant pathologic structure in any part of the body. 